\title{
IPSS Risk Category Intermediate-2
}

National Cancer Institute

\section{Source}

National Cancer Institute. IPSS Risk Category Intermediate-2. NCI Thesaurus. Code C139303.

An International Prognostic Scoring System for Myelodysplastic Syndrome risk category that predicts a high-interdemiate likelihood for progression. 